\title{
Aortic stenosis and the case of the missing handbag
}

Peter Perkins

\begin{abstract}
Aortic stenosis is now the most common type of valvular heart disease in Europe and North America. Calcific aortic stenosis affects $2-7 \%$ of people aged over 65 years. Dyspnoea, chest pain, and syncope require investigation and surgery is the preferred option for suitable individuals. Operative mortality is $3-5 \%$ for those aged under 70 years and $5-15 \%$ in older adults. The case reported here illustrates the issues raised when a GP's patient unexpectedly collapses in a public place and other professional agencies become involved. Relevant UK medico-legal requirements of the vehicle licensing agency and the new guidance related to antibiotic prophylaxis and heart valve disease are also discussed.

Keywords

aortic valve stenosis; automobile driving; confidentiality; crime.
\end{abstract}

\section{INTRODUCTION}

Medicine is not too dissimilar to police work: a set of symptoms/signs (clues) is elicited by taking a careful history plus an examination (of the scene), following which a diagnosis is made (crime is solved). Dialogue between the two services happens infrequently in ordinary general practice. This case illustrates an example of such cooperation in an incident involving an older woman who collapsed due to severe aortic stenosis.

\section{CASE HISTORY}

A previously fit, active, and independent 95-yearold woman had recently been diagnosed with severe aortic stenosis and angina. She failed to arrive for a mid-morning consultation with myself,

P Perkins, MRCS, FRCGP, GP Principal, Southbourne Surgery, Bournemouth.

Address for correspondence

Dr Peter Perkins, Southbourne Surgery, 17 Beaufort Road, Bournemouth BH6 5BF.

E-mail: peter.perkins@dorset.nhs.uk

Submitted: 15 May 3008; Editor's response: 7 July 2008; final acceptance: 24 November 2008.

(C)British Journal of General Practice 2009; 59: 266-267.

DOI: 10.3399/bjgp09X420347 her GP. She seldom saw a doctor, and was always punctual and 'sorry to bother anyone'. Some 20 minutes after her scheduled appointment time, the receptionist took a phone call from a nearby GP surgery asking for this patient's medical details. She had apparently collapsed on the pavement outside and a kindly neighbour had taken her to the nearer GP surgery, which - in view of her collapse and head injury - subsequently arranged for her transfer by ambulance to the local accident and emergency department.

Later that same morning two police officers arrived to interview me as her GP, requesting further information about the case. It transpired that she had been unable to park her car in the other surgery car park, as it was full. No one had actually seen her collapse, she had her car keys in her pocket but arrived at the hospital without a handbag. As 'all women carry a handbag', the question of whether she had fallen or was assaulted and robbed needed to be answered. By this time she was in the accident and emergency department and having brain CT due to contusions to the head.

In the circumstances, I thought it reasonable to inform the police of her recent hospital attendance and her diagnosis of angina and severe aortic stenosis. Due to her failure to find a parking space at the surgery and her possible haste to arrive on time for her consultation, her cardiac condition may well have caused her collapse. This explanation seemed plausible and, until she had recovered sufficiently to be questioned further, it would obviate the urgency to invoke a third party under the assumption that there had been some foul play with the intention of stealing a handbag. It could save valuable police time and avoid investigating a crime that never took place.

After a short spell in hospital the woman was discharged to a local intermediate care unit before returning to her own home. Although she no longer drove her car, her indomitable spirit remained. Three months later she died peacefully at home from congestive cardiac failure, aortic stenosis, and, quite probably, old age.

\section{DISCUSSION}

Aortic stenosis has become the most frequent type 
of valvular heart disease in Europe and North America. ${ }^{1}$ The most common cause is calcific aortic stenosis in older people $(2-7 \%$ of the population aged over 65 years). ${ }^{1}$ Careful assessment of individual patients with aortic stenosis is critical for appropriate management.

\section{Diagnosis}

Auscultation alone is unreliable as accuracy can depend on examiner expertise. In addition, although the absence of a murmur over the right clavicle may help to exclude aortic stenosis, ${ }^{2}$ with severe aortic stenosis, a soft systolic murmur may be caused by poor left ventricle function. ${ }^{3}$ Shortness of breath, angina, dizziness, or syncope require investigation: electrocardiogram, possible exercise testing, echocardiography, renal function, and assessment of comorbidity. Doppler echo is the preferred technique to assess severity of aortic stenosis and a valve area $<1.0 \mathrm{~cm}^{2}$ is considered severe. ${ }^{1}$

\section{Management}

As soon as symptoms develop, the prognosis is poor and mortality is significant. The average survival rate is 3 years after the onset of angina pectoris or syncope in severe aortic stenosis. ${ }^{4}$ Aortic valve replacement is the treatment of choice with an operative mortality of $3-5 \%$ in patients under 70 years and $5-15 \%$ in older adults. ${ }^{1}$ Mortality is increased in older age, females, left ventricular dysfunction, co-existing coronary artery disease, and when surgery is performed as an emergency. In those patients who are considered unsuitable for aortic valve replacement, balloon valvuloplasty may be an option. ${ }^{5}$

Medical management in this patient consisted of low-dose, long-acting nitrates. These must be used with caution as they may cause orthostatic hypotension and syncope. The use of diuretics in patients with coronary heart failure may decrease cardiac output and cause hypotension. Data are conflicting regarding the use of angiotensinconverting enzyme inhibitors and, if there is coexisting coronary heart failure, angiotensin-II receptor antagonists should be avoided. The same applies to beta-blockers. ${ }^{1}$ The routine use of prophylactic antibiotics to prevent bacterial endocarditis is no longer recommended. ${ }^{6}$

Vehicle licensing regulations in the UK state that age is no bar to holding a valid driving licence but, at the age of 70 years, confirmation is needed that no medical disability is present. Thereafter, a 3-year licence is issued subject to satisfactory answers to the medical questions on an application form. ${ }^{7}$ Driving must cease:
- if angina occurs at rest, with emotion, or at the wheel,

- if symptoms of heart failure may distract the driver,

- if there is loss of consciousness or altered awareness, and

- in heart valve disease associated with any other disqualifying condition such as those mentioned.

At the time, it was not possible to seek the patient's consent to give someone else information about her medical condition. However, disclosure to another responsible person was deemed in her best interests and would assist in determining whether a serious crime had been committed against her. ${ }^{8}$

\section{CONCLUSION}

I could not find a definitive reference to substantiate that women always carry a handbag, although the assumption made by the police would seem to me reasonable - that is, that most women do and it is the exception to the 'rule' who doesn't. The patient was, in fact, not carrying one. Finally, during the interview with the police, I could not help thinking about Oscar Wilde's Lady Bracknell in The Importance of Being Earnest - a thought I kept to myself.

\section{Consent}

The patient provided the author with consent before she died

\section{Competing interests}

The authors have stated that there are none.

Discuss this article

Contribute and read comments about this article on the Discussion Forum: http://www.rcgp.org.uk/bjgp-discuss

\section{REFERENCES}

1. Vahanian A, Baumgartner H, Bax J, et al. Guidelines on the management of valvular heart disease. The Task Force on the Management of Valvular Heart Disease of the European Society of Cardiology. Eur Heart J 2007; 28(2): 230-268.

2. Etchells E, Glenns V, Shadowitz S, et al. A bedside clinical prediction rule for detecting moderate or severe aortic stenosis. $J$ Gen Intern Med 1998; 13(10): 699-704

3. Das P, Pocock C, Chambers J. The patient with a systolic murmur: severe aortic stenosis may be missed during cardiovascular examination. QJM 2000; 93(10): 685-688.

4. Braunwald E. On the natural history of severe aortic stenosis. $J$ Am Coll Cardiol 1990; 15(5): 1018-1020.

5. Aronow WS. Recognition and management of aortic stenosis in the elderly. Geriatrics 2007; 62(12): 23-32.

6. National Institute of Health and Clinical Excellence. Prophylaxis against infective endocarditis: antimicrobial prophylaxis against infective endocarditis in adults and children undergoing interventional procedures. Clinical Guideline 64. London: NICE, 2008. http://www.nice.org.uk/nicemedia/pdf/CG64NICEguidance.pdf (accessed 4 Mar 2009).

7. Drivers Medical Group. For medical practitioners: at a glance guide to the current medical standards of fitness to drive. Swansea: Driver and Vehicle Licensing Agency, 2008.

8. General Medical Council. Confidentiality. Review of the GMC's confidentiality guidance. London: GMC, 2004. http://www.gmcuk.org/confidentiality/index.asp (accessed 4 Mar 2009). 